\title{
Prescribing Pattern of Antimicrobial Agents in Neonates at Nepalgunj Medical College, Kohalpur, Banke, Nepal
}

\author{
Neupane $G P^{1}$, Rai $M^{2}$, Dhami $\mathrm{DB}^{1}$, Singh $\mathrm{R}^{1}$
}

\begin{abstract}
Introduction: Neonates are most vulnerable to infections due to poor immune system leading to high morbidity and mortality, which justifies early diagnosis and prompt treatment with antibiotics. Antibiotics are the most frequently used drugs in Neonatal Intensive care units. Aim and Objective: The objective of present study was to identify the pattern of use of antimicrobial agents in neonates at the neonatal intensive care unit (NICU) of NGMC. Materials and Methods: A hospital-based, retrospective study (prescription audit) was conducted over a period of 5-month duration at Nepalgunj Medical College by reviewing case records of NICU. Data were collected and analyzed. Results: A total of 150 case records were reviewed and were included in the study. Out of the 150, Neonates 86 (57.33\%) were male babies and 64 (42.67\%) were female babies. Maximum number (72.66\%) neonates admitted to NICU were of low birth weight and most common reason for NICU admission was neonatal septicaemia. The majority of neonates (68.67\%) received 2 antimicrobial agents (AMAs), 21.33\% received 3 AMAs and average number of antibiotic per case was 2.44. The most commonly prescribed antimicrobial agent was Cefotaxime (58.66\%), followed by Amikacin (48\%), Ceftriaxone (32\%). In fixed dose combination Piperacillin + Tazobactum (28\%) was most commonly prescribed. All of the antimicrobial agents were prescribed by brand name. Conclusion: Measures need to be undertaken to encourage physicians to prescribe AMAs in generic names to minimize health care cost. Present study suggests that Antibiotics policy to be framed \& periodically reviewed: to reduce unnecessary use of antibiotics and associated problems.
\end{abstract}

Key words: Antimicrobial agents, neonates, prescription

\section{INTRODUCTION}

Over 9 million deaths occur each year in the perinatal and neonatal periods globally and $98 \%$ of these deaths take place in the developing world. Nepal has a high neonatal mortality rate (NMR) of 38.6 per 1000 live births (2001). Two thirds of the newborn deaths usually occur in the first week of life (early neonatal death). Newborn survival has become an important issue to improve the overall health status and for achieving the millennium developmental goals of a developing country like Nepal ${ }^{1}$.

The use of drugs in newborns admitted to Neonatal Intensive Care Units (NICUs) is characterized by a great variability in the management of the most common diseases and is a widespread phenomenon observed both within and between different countries ${ }^{2}$. Neonates are a special group of population for dosing because they have a rapidly changing body surface area and weight; a rapidly developing system of drug

1. Dr. Ganesh Prasad Neupane

2. Dr. Maya Rai

3. Dr. Dabal Bahadur Dhami

4. Dr. Ritesh Singh

Address for correspondence:

Dr. Ganesh Prasad Neupane

Department of Pharmacology

Nepalgunj Medical College Teaching Hospital

Chisapani, Banke, Nepal

Email: ganeshpn2003@yahoo.com absorption, metabolism and excretion and inability to communicate with the provider ${ }^{3}$.

Although it has been shown that patterns of drug utilization of antibiotic in neonatal intensive care are changing dynamically, current data on drug utilization patterns in neonatal intensive care are limited ${ }^{4}$. There is no universally accepted and standardized guidelines regarding the rational prescribing and individualizing the medication in neonatal intensive care. For the purpose of drug therapy, pediatric age group especially neonates, remains in controversies mainly due to lack of standard drug prescribing information for several drugs. Unfortunately for children, most drug manufacturer insert contain precautionary disclaimer, because safety \& efficacy in children have not been established.

Infants and children are among the most vulnerable population groups to contract illnesses. The use of antimicrobial agents, especially antibiotics has become a routine practice for the treatment of paediatric illnesses ${ }^{2,3}$. The key role of antibiotics for the treatment of infectious diseases that are prevalent everywhere in developing countries may not be denied. However, there are also reports of an irrational use of antibiotics which may even lead to infections that are worse than the originally diagnosed ones. The pediatricians and other medical personnel who provide health care for infants and children in developing countries confront a number of challenges during the day to day practice of medicine due to the shortage of appropriate drugs and other facilities ${ }^{4,5}$. The rising 
incidence of bacterial resistance to common antibiotics, particularly, multi- drug resistant pneumococci, has prompted the need to use antibiotics judiciously in paediatric practice. Many of the antibiotics are unnecessarily prescribed for viral infections such as common cold. In a Kentucky study, 60 percent of patients were prescribed antibiotics for the common cold. ${ }^{6}$

Developing countries have limited funds available for health care and drugs hence it becomes very important to prescribe drugs rationally, so that the available funds can be utilized optimally. Most of reported drug utilization studies have been carried out in adult patients with only a few being reported from pediatric patients. So present study is taken up to evaluate the drug prescribing pattern of antimicrobial agents seen in patients admitted to NICU of Nepalgunj medical college teaching hospital kohalpur banke Nepal.

\section{Materials and Methods}

A hospital-based, retrospective study (prescription audit) was conducted between December 2016 to April 2017 in the 150 case records of neonates patients admitted to NICU at Nepalgunj Medical College Teaching Hospital Kohalpur for a period of five month.

Necessary permission from the concerned authorities was obtained for data collection. The neonate (0-4 week age) who were prescribed antimicrobial agent (AMA) were included in the study. Neonate with Incomplete patient case sheet, discharged within $24 \mathrm{hrs}$. of admission, transferred to other specialty intensive care units, patients aged more than 4 weeks, patient who died before hospital discharge were excluded from the present study. To evaluate the drug prescribing pattern, a data collection pro forma sheet was prepared. Data were collected through review of case records of neonates admitted and treated in the NICU of pediatrics department.

Consecutive 150 case records of neonates admitted and treated in the NICU between December 2016 and April 2017 were obtained from the medical records department of the hospital. Study parameter were Demographic data: including age and sex of the baby and address, provisional and final diagnoses, group, number and type of antimicrobial agents prescribed per record, dosage, durations, and frequency of all AMAs, Route of administration and drug prescribed by brand or generic drugs.

Collected data were entered in Microsoft Office Excel 2007 and analyzed using SPSS Inc. Statistical Software Version 16.0. Descriptive statistical analysis was done using proportion, percentages and mean \pm standard deviation.

\section{RESULTS}

Out of the 150, Neonates 86 (57.33\%) were male babies and 64 (42.67\%) were female babies. Maximum number $(72.66 \%)$ neonates admitted to NICU were of low birth weight. Table [I] and most common cause of NICU admission was neonatal septicaemia (47.33\%) followed by perinatal birth asphaxia (12\%) Table [II].

The Number of antimicrobials prescribed to a neonate during the course of the therapy ranged from 2 to 5 , highest number of patients, i.e. $103(68.67 \%)$ received 2 antimicrobials, which was followed by 32 patients $(21.33 \%$ ) received 3 antimicrobials, 11 patients $(7.33 \%$ ) received 4 antimicrobials etc (Figure 1 ).

\begin{tabular}{|l|c|c|}
\hline Catagory & $\begin{array}{c}\text { Number } \\
\text { of Neonates }\end{array}$ & Percentage \\
\hline $\begin{array}{l}\text { Normal } \\
(>2500 \mathrm{~g})\end{array}$ & 26 & 17.33 \\
\hline $\begin{array}{l}\text { Low birth weight } \\
(1500-2499 \mathrm{~g})\end{array}$ & 109 & 72.66 \\
\hline $\begin{array}{l}\text { Very low birth weight } \\
(1000-1499 \mathrm{~g})\end{array}$ & 14 & 9.34 \\
\hline $\begin{array}{l}\text { Extreme low birth weight } \\
(<1000 \mathrm{~g})\end{array}$ & 150 & 100 \\
\hline Total & & \\
\hline
\end{tabular}

Table I: Birth weight in grams (g) and maturity wise disitibution of Neonates

\begin{tabular}{|l|c|}
\hline Disease & Number(\%) \\
\hline Neonatal Jaundice & $17(11.33 \%)$ \\
\hline Neonatal Sepsis & $71(47.33 \%)$ \\
\hline Respiratory Distress syndrome & $5(3.33 \%)$ \\
\hline Perinatal birth Asphyxia & $18(12 \%)$ \\
\hline Pneumonia & $7(4.68 \%)$ \\
\hline Convulsions & $6(4 \%)$ \\
\hline Meconium Aspiration Syndrome & $12(8 \%)$ \\
\hline Prematurity & $14(9.33 \%)$ \\
\hline Total & $150(100 \%)$ \\
\hline
\end{tabular}

Table II: Disaease pattern in The NICU

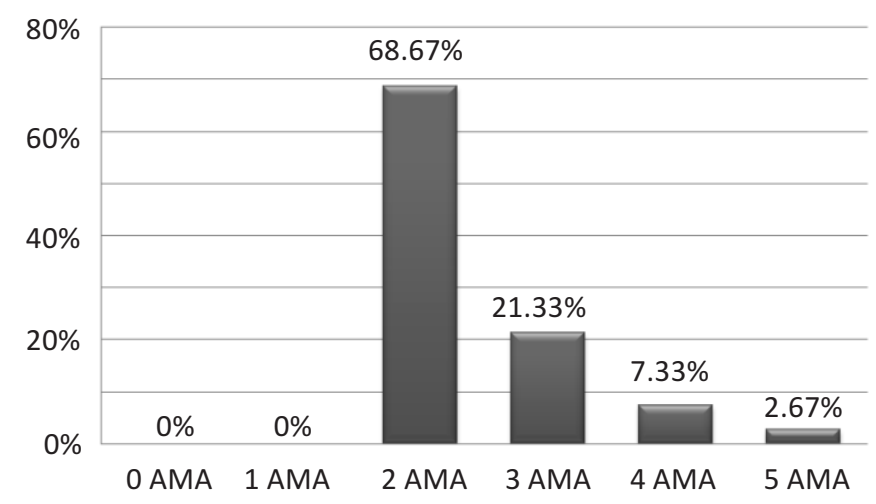

Figure 1: Number of antimicrobial agents (AMA) prescribed 


\begin{tabular}{|l|c|}
\hline Total number of patients & $\mathbf{1 5 0}$ \\
\hline Total Number of Antimicrobial agents & 366 \\
\hline $\begin{array}{l}\text { Mean Number of antimicrobial agents } \\
\text { per patients }\end{array}$ & 2.44 \\
\hline $\begin{array}{l}\text { Total number of antimicrobial agents } \\
\text { prescribed by generic name }\end{array}$ & $\mathrm{Nil}$ \\
\hline Total number of fixed dose combinations & 60 \\
\hline
\end{tabular}

Table III : Description of General Prescription Data

\begin{tabular}{|l|c|}
\hline Antimicrobial agent & $\begin{array}{c}\text { Number and } \\
\text { percentage of } \\
\text { Neonates exposed ( } \mathbf{n = 1 5 0 )}\end{array}$ \\
\hline Cefotaxime & $88(58.66 \%)$ \\
\hline Ampicillin & $14(9.33 \%)$ \\
\hline Amikacin & $72(48 \%)$ \\
\hline Gentamicin & $16(10.66 \%)$ \\
\hline Ceftriaxone & $48(32 \%)$ \\
\hline Cloxacillin & $9(6 \%)$ \\
\hline Vancomycin & $34(22.66 \%)$ \\
\hline Meropenem & $14(9.33 \%)$ \\
\hline Metronidazole & $2(1.33 \%)$ \\
\hline Imepenem & $9(6 \%)$ \\
\hline
\end{tabular}

Table IV: Prescribing frequency of systemic antimicrobial agents in the NICU

\begin{tabular}{|l|c|}
\hline Antimicrobial agent & $\begin{array}{c}\text { Number and } \\
\text { prescription (\%) }\end{array}$ \\
\hline Piperacillin + Tazobactum & $42(28 \%)$ \\
\hline Cefoperazone + Sulbactum & $11(7,33 \%$ \\
\hline Ampicillin + Cloxacillin & $7(4.66 \%)$ \\
\hline
\end{tabular}

Table V: Prescription pattern of fixed dose drug combination Antibiotics in NICU

In 150 patients, 366 times antimicrobials were prescribed and the mean of antimicrobial prescribed per record was 2.44. All $(100 \%)$ were prescribed by brand name and all the antimicrobial agents were administered by intravenous route. The number of fixed dose combinations was 60 [Table III].

Fourteen different types of AMAs were utilized. (Fixed drug combinations such as piperacillin + tazobactam prescriptions were considered as a single type of AMA for analysis). Cefotaxime (58.66\%), amikacin (48\%), Ceftiaxone (32\%), Vancomycin (22.66\%) were the most frequently prescribed AMAs in the NICU (Table IV). In Fixed dose combinations the Piperacillin + Tazobactum combination (28\%) was most commonly prescribed fixed dose combinations. [Table V].

\section{DISCUSSION}

In present study, among the NICU patients, male preponderance $(57.33 \%$ ) in admissions was noticed .These finding were similar to the finding of Amin et.al ${ }^{7}$, Neubert et.al ${ }^{4}$, Kumar et.al ${ }^{8}$. It have been found that morbidity and mortality rates are higher in males than in females throughout life which could be attributed to stronger humoral and cellular immune response to infection or antigenic stimulation in females than in males ${ }^{9}$.

This study showed that majority of the patient $(72.66 \%)$ had low birth weight and main cause of admission to NICU was due to neonatal septicaemia (47.33\%). These findings were similar to the study of Amin et.al ${ }^{7}$, Pandiamunian et.al ${ }^{10}$, Uppal et $\mathrm{al}^{11}$. Which may be because of the fact that during early neonatal age neonates are more susceptible to infection. Furthermore, prematurity is a major cause of low birth weight in preterm babies and these two factors, i.e. prematurity and low birth weight may be responsible for higher chances of infection ${ }^{7}$.

Majority of the patients were given either 2 (68.67\%) and 3 (21.33\%) antimicrobials and average number of antimicrobial per prescription was 2.44 which was similar to study of Neubert et.al ${ }^{4}$, Amin et.al ${ }^{7}$. Average number of drug is an important indicator for assessing rationality of prescription. It is preferable to keep the mean number of drugs per prescription as low. The WHO recommends that the average number of drugs per prescription should be less than 2 . The average number of drugs per prescription value should be as low as possible to prevent the unfavourable outcomes of polypharmacy such as increased risk of drug interactions, increased cost of therapy, non-compliance and emergence of resistance in case of use of antimicrobials ${ }^{12}$.

All of the drugs were prescribed by brand name which unnecessarily adds to the cost of therapy. Increasing generic prescribing would rationalize the use and reduce the cost of drugs $s^{13}$.

All neonates received drugs via parenteral (intravenous) route. This result complies with prospective study done by Amin et.al ${ }^{7}$. Use of oral route in neonates is usually not preferred and in neonates oral administration is difficult. ${ }^{7}$

Most frequently prescribed antimicrobials were cefotaxime in $58.66 \%$ of patients, and amikacin in $48 \%$ of patients. These findings were similar to study of Amin et $\mathrm{al}^{7}$, Pandiamunian et.al ${ }^{10}$, Chatterjee et.al ${ }^{14}$. It is generally established that combination therapy of penicillin/cephalosporin and aminoglycoside is effective. Due to emerging resistance to ampicillin, cephalosporin and aminoglycoside combination is recommended as first-line therapy ${ }^{15}$. Higher prescription rate of cephalosporin could be attributed to its broad spectrum of activity and tolerance across all age group ${ }^{16}$. 
Aminoglycoside like amikacin and Gentamycin were also among the most frequently utilized group of antimicrobials. In combination with either a cephalosporin or penicillin, one of the aminoglycosides were prescribed to the majority of the neonates who received AMAs in the NICU. This is in accordance with other study reports, wherein gentamicin was found to be widely used in combination with $\beta$-lactam antibiotics, especially crystalline penicillin and ampicillin as this combination will provide synergistic activity against the most common pathogens isolated in early onset sepsis (e.g., Klebsiella pneumoniae and coagulase-negative Staphylococci $)^{17,18}$. The fixed dose combination of Piperacillin and Tazobactam was used most commonly in $28 \%$ in the neonates. These finding was similar to study of Subash et al. ${ }^{19}$, Fanos et $\mathrm{al}^{20}$. This fixed dose combinations may be prescribed for treatment of severe infection due to gram negative organism like Pseudomonas and other beta-lactamase producing organisms.

\section{LIMITATIONS}

The limitations of the study are shorter duration of study and study was conducted in single center only. Seasonal infection and geographic area also have a role on infection which may have impact on antimicrobial usage.

\section{CONCLUSIONS}

Prescription aduit studies are powerful exploratory tools to ascertain the role of drugs in society and create sound sociomedical and health economic basis for health care decisionmaking. There is little information is available regarding the extent and pattern of Antimicrobial drug use in NICU. There is a great need to study the drug utilization pattern in neonates. The study of antibiotic utilization pattern in our study showed that Cefotaxime, Amikacin, Ceftriaxone and Piperacillin + Tazobactum were used more in our NICU. The study concludes the prescription pattern at our neonatal intensive care unit complies with international studies. It is being evident from the study result that AMAs are prescribed predominantly in brand names in the NICU. Measures need to be undertaken to encourage physicians to prescribe AMAs in generic names to minimize health care cost. Present study suggests that Antibiotics policy to be framed \& periodically reviewed: to reduce unnecessary use of antibiotics and associated problems.

\section{REFRENCES}

1. Shresth M, Bajracharya BL, Manandhar DS. A Study of Early Neonatal Deaths at Kathmandu Medical College Teaching Hospital. J. Nepal Paediatr. Soc. 2007.Vol 27(2), p.79-82.

2. Cuzzolin L. Variability in drug use among newborns admitted to NICUs: a proposal for a European multicentre study. J Pediatr Neonat Individual Med. 2014; 3(1): 1-3. e030122. doi: 10.7363/030122.

3. Jain S, Basu S, Parmar VR. Medication Errors In Neonates Admitted In Intensive Care Unit And Emergency Department. Indian J Med Sci 2009 April; 63(4): 145-51.
4. Neubert A, Lukas K, Leis T, Dormann H, Brune K, Rascher W. Drug utilisation on a preterm and neonatal intensive care unit in Germany: a prospective, cohort-based analysis. Eur J Clin Pharmacol 2010; 66: 87-95.

5. Christensen ML, Helms RA, Chesney RW. Is Pediatric Labeling Really Necessary? J Pediatr 1999 Sept; 104(3): 593-97.

6. Shankar PR, Partha P, Dubey AK, Mishra P, Deshpande VY. Intensive care unit drug utilization in a teaching hospital in Nepal. Kathmandu Uni Med J 2005; 3(10):130-37.

7. Amin AJ, Shah PC, Asari PD, Malam P, Kalkoti V, Behl AB. Drug utilization study of antimicrobial agents in patients of neonatal sepsis in neonatal intensive care unit at a tertiary care hospital in western part of India. Int J Basic Clin Pharmacol 2015;4:895-902.

8. Kumar P, Walker JK, Hurt KM, Bennett KM, Grosshans N, Fotis MA. Medication use in the neonatal intensive care unit: current patterns and off-label use of parenteral medications. J Pediatr. 2008;152(3):412-5.

9. Muenchhoff M, Gaulder P. Sex difference in Pediatric Infectious Diseases. The Journal of Infectious Diseases. 2014; 209(S3): 1206.

10. Pandiamunian J, salwe KJ, Somasundaram G, kolasani BP. A study on prescribing pattern of antimicrobial agents in the neonatal intensive care unit of a tertiary care teaching hospital in puducherry, south india. Asian J Pharm Clin Res. 2016 ;9(5) :217220.

11. Uppal R, Chhabra A, Narang A. Pattern of drug use in neonatal intensive care unit. Indian Pediatr. 1998;35(7):647-9.

12. Using Indicators To Measure Country Pharmaceutical Situations. Fact Book on WHO Level I and Level II monitoring indicators. Geneva, World Health Organization, 2006.

13. Quick JD, Hogerzeil HV, Velasquez G, Rago L. Twenty-five years of essential medicines. Bull World Health Organ. 2002;80(11):9134.

14. Chatterjee S, Mandal A, Lyle N, Mukherjee S, Singh AK. Drug utilization study in a neonatology unit of a tertiary care hospital in eastern India. Pharmacoepidemiol Drug Saf 2007;16(10):1141-5.

15. Kaushik SL, Parmar VR, Grover N, Grover PS, Kaushik R. Neonatal sepsis in hospital born babies. J Commun Dis. 1998;30(3):147-52.

16. Goodman \& Gilman's. The Pharmacological basis of Therapeutics. McGraw-Hill Medical Publishing Division. 11th Edition, 2001; 1179-1206.

17. Fullas F, Padomek MT, Thieman CJ, Van Gorp AE. Comparative evaluation of six extended-interval gentamicin dosing regimens in premature and full-term neonates. Am J Health Syst Pharm 2011;68(1):52-6.

18. Chattopadhyay B. Newborns and gentamicin - how much and how often? J Antimicrob Chemothe 2002;49(1):13-6.

19. Subash KR, Shanmugapriyan S. A study on prescription of antibiotics utilization in neonatal intensive care at a tertiary care center. Int J Med Res Health Sci. 2015;4(2):265-268.

20. Fanos V, Cuzzolin L, Atzei A, and Testa M. Antibiotics and antifungals in neonatal intensive care units: a review. J Chemother. 2007; 19(1):5-20. 